\title{
ANALISIS PERHITUNGAN DEBIT MUATAN SEDIMEN (SUSPENDED LOAD) PADA DAERAH IRIGASI LEKOPANCING KABUPATEN MAROS
}

\author{
Nurul Afdhaliah ${ }^{1}$, Faridah ${ }^{1}$ dan Ahmad Munir ${ }^{1}$ \\ Program Studi Teknik Pertanian, Universitas Hasanuddin Makassar
}

\begin{abstract}
ABSTRAK
Daerah Irigasi Lekopancing terletak di Kecamatan Tanralili, Kabupaten Maros. Irigasi ini mengairi lahan pertanian seluas 3.626 ha. Penggunaan efisiensi irigasi Lekopancing mengalami penurunan yang drastis selama beberapa tahun terakhir akibat adanya penumpukan sedimen sepanjang saluran. Tujuan dari penelitian ini adalah menghitung debit muatan sedimen melayang (suspended load) dengan menggunakan metode lapangan, pendekatan Lane dan Kalinske, dan pendekatan Einsten dan membandingkan hasil perhitungan dengan hasil yang berada di lapangan yang terdapatdi saluran irigasi tersebut. Metode penelitian yang digunakan yaitu dengan membagi 3 segmen irigasi dan melakukan pengambilan sampel sedimen kemudian menghitung sedimen yang ada di saluran Lekopancing dengan cara menganalisis data menggunakan pendekatan Lane dan Kalinske dan pendekatan Einstein untuk memperkirakan seberapa besar sedimen melayang di daerah irigasi tersebut. Hasil yang didapatkan dari penelitian ini yaitu, debit muatan sedimen melayang tertinggi berada di segmen B yaitu $1,14 \times 10^{-4} \mathrm{~kg} / \mathrm{s}$ (metode langsung), $1,6 \times 10^{-3} \mathrm{~kg} / \mathrm{s}$ (Pendekatan Lane dan Kalinske), dan $3,7 \times 10^{-3} \mathrm{~kg} / \mathrm{s}$ (Pendekatan Einstein). Hasil perbandingan hubungan korelasi dari kedua pendekatan yaitu pendekatan Einstein memiliki korelasi yang baik dengan pengukuran langsung dan pendekatan Lane dan Kalinske memiliki korelasi yang kurang baik.
\end{abstract}

Kata kunci: Irigasi Lekopancing, suspended load, pengukuran langsung, pendekatan Lane dan Kalinske, pendekatan Einstein.

\section{PENDAHULUAN}

\section{Latar Belakang}

Irigasi menjadi salah satu input atau masukan dalam sebuah pengelolaan lahan sebagai bagian dari budidaya pertanian. Secara keseluruhan, irigasi tergabung dalam jaringan irigasi. Jaringan irigasi adalah kesatuan saluran, bangunan, dan bangunan pelengkapnya yang digunakan untuk mendistribusikan air yang berasal dari bendungan ke lahan pertanian yang dimiliki masyarakat. Dengan demikian, kebutuhan air untuk sawah/ladang para petani akan terjamin dengan adanya saluran irigasi. Hal ini akan menjadi lebih optimal apabila kondisi irigasi tersebut berada dalam keadaan yang efisien.

Kondisi irigasi di Indonesia sangat memprihatinkan. Menurut data Direktorat Jenderal Sumber Daya Alam inventarisasi Jurnal AgriTechno (Vol. 10, No. 2, Oktober 2017) kondisi jaringan irigasi Indonesia, terdapat $>40 \%$ jaringan irigasi di Indonesia mengalami kerusakan dan menyebabkan RI kehilangan produksi padi mencapai 4,5 juta ton per tahun. Dan salah satu penyebab kerusakan tersebut akibat adanya pendangkalan saluran. Hal ini disebabkan di dalam saluran irigasi, terdapat aliran yang mengangkut material sedimen yang berasal dari proses erosi yang terbawa oleh aliran air dan akhirnya menyebabkan pendangkalan. Akibatnya sedimentasi yang terdapat di dalam aliran tersebut akan mempercepat umur penggunaan saluran irigasi.

$$
\text { Daerah Irigasi Lekopancing }
$$
terletak di Kecamatan Tanralili, Kabupaten Maros. Irigasi ini mengairi lahan pertanian seluas 3.626 ha. Penggunaan efisiensi irigasi Lekopancing mengalami penurunan yang drastis selama beberapa tahun 
terakhir akibat adanya penumpukan sedimen sepanjang saluran.

Berdasarkan uraian tersebut maka penelitian mengenai "Analisis Perhitungan Debit Muatan Sedimen (Suspended Load) Pada Daerah Irigasi Lekopancing Kabupaten Maros" kemudian dilakukan untuk mengetahui seberapa besar debit sedimen (suspended load) yang terjadi di Irigasi Lekopancing yang lokasi analisisnya berada di Kecamatan Tanralili Kabupaten Maros dan perbandingan antara hasil perhitungan dengan hasil lapangan.

\section{Rumusan Masalah}

Permasalahan yang akan dibahas dalam penelitian ini adalah seberapa besar debit sedimen (suspended load) yang terjadi di saluran irigasi Lekopancing yang lokasi analisisnya berada di Kecamatan Tanralili Kabupaten Maros.

\section{Tujuan dan Kegunaan}

Tujuan yang ingin dicapai dari penelitian ini adalah sebagai berikut:

a. Menghitung debit sedimen melayang (suspended load) dengan menggunakan metode lapangan, metode pendekatan Lane dan Kalinske, dan metode pendekatan Einsten yang terdapat di saluran irigasi Lekopancing Kabupaten Maros.

b. Membandingkan hasil perhitungan dengan hasil yang berada di lapangan. Kegunaan dari penelitian ini yaitu sebagai bahan referensi bagi dinas pekerjaan umum dan ketata wilayahan dalam penanggulangan dan pencegahan kerusakaran irigasi saluran Lekopancing.

\section{TINJAUAN PUSTAKA}

\section{Irigasi}

Irigasi adalah usaha untuk memperoleh air yang menggunakan bangunan dan saluran buatan untuk keperluan penunjang produksi pertanian (Mawardi dalam Rangga, 2012).
Tujuan utama irigasi adalah mewujudkan kemanfaatan air yang menyeluruh, terpadu, dan berwawasan lingkungan, serta meningkatkan kesejahteraan masyarakat, khususnya petani (Peraturan Pemerintah tahun 2001, BAB I pasal 2).

Dalam pemenuhan kebutuhan air irigasi perlu diusahakan secara menyeluruh dan merata, khususnya apabila ketersediaan air terbatas. Pada musim kemarau misalnya banyak areal pertanian yang tidak ditanami karena air yang dibutuhkan tidak mencukupi (Rangga, 2012).

\section{Sistem Irigasi}

Pada umumnya sistem irigasi di Indonesia pengaliran airnya dengan sistem gravitasi dan sistem jaringannya ada 3 golongan :

1. Sistem Irigasi Sederhana

Sistem irigasi ini baik bangunan maupun pemeliharaannya dilakukan oleh para petani dan pada umumnya jumlah arealnya relative kecil. Biasanya terdapat dipegunungan, sedangkan sumber airnya didapat dari sungai-sungai kecil yang airnya mengalir sepanjang tahun.

2. Sistem Irigasi Sederhana Teknis

Sistem irigasi ini seluruh banguan yang ada didalam jaringan irigasi setengan teknis konstruksinya bisa permanent atau setengah permanent hanya tidak dilengkapi dengan pintu air dan alat pengukur debit.

3. Sistem Irigasi Teknis

Sistem irigasi ini seluruh bangunan yang ada didalam jaringan irigasi teknis semua konstruksinya permanent dan juga dilengkapi dengan pintu-pintu air dan alat ukur debit, dimana pembagian airnya bisa diatur dan bisa diukur disesuaikan dengan kebutuhan, sehingga pembagian/pemberian air ke sawah-sawah dilakukan dengan tertib dan merata.

Di samping itu untuk menjamin tidak kebanjiran, dibuat jaringan pembuang 
tersier, sekunder dan induk, yang nantinya air tersebut dialirkan langsung ke sungai. Saluran ini juga berfungsi untuk membuang air sisa pemakaian dari sawah (Radjualini, 2008).

\section{Debit}

Debit aliran sungai $(Q)$ adalah jumlah air yang mengalir melalui tampang lintang sungai tiap satu satuan waktu, biasanya dinyatakan dalam meter kubik per detik $\left(\mathrm{m}^{3} / \mathrm{s}\right)$. Debit sungai dengan distribusinya dalam ruang dan waktu merupakan inforrnasi penting yang diperlukan dalam perencanaan bangunan air dan pemanfaatan sumberdaya air. Mengingat bahwa debit aliran sangat bervariasi dari waktu ke waktu, maka diperlukan data pengamatan debit dalam waktu panjang (Triatmodjo, 2010).

Debit aliran diperoleh dengan mengalikan luas tampang aliran $(A)$ dan kecepatan aliran $(V)$. Kedua parameter tersebut dapat diukur pada suatu tampang lintang (stasiun) di sungai. Luas tampang aliran diperoleh dengan mengukur elevasi permukaan air dan dasar sungai. Kecepatan aliran diukur dengan menggunakan alat ukur kecepatan seperti current meter, pelampung, atau peralatan lain (Triatmodjo, 2010).

$$
\mathrm{Q}=\mathrm{A} \cdot \mathrm{V}
$$

Dimana:

$$
\begin{aligned}
& \mathrm{Q}=\underset{\text { debit aliran yang diperhitungkan }}{ }\left(\mathrm{m}^{3} / \mathrm{s}\right) \\
& \mathrm{A}=\text { luas penampang }\left(\mathrm{m}^{2}\right) \\
& \mathrm{V}=\text { kecepatan rata-rata aliran }(\mathrm{m} / \mathrm{s})
\end{aligned}
$$

Pengukuran debit dikatakan secara tidak langsung apabila kecepatan alirannya tidak diukur langsung, akan tetapi dihitung berdasarkan rumus hidraulis debit dengan rumus manning, chezy, serta Darcy Weisbach. Salah satu rumusnya yaitu rumus Manning dinyatakan dalam bentuk persamaan sebagai berikut :

$$
\mathrm{V}=\frac{1}{n} x R^{2 / 3} x S^{1 / 2}
$$

Dimana:

$$
\mathrm{V}=\operatorname{Kecepatan} \text { Aliran (m/dtk) }
$$

$\mathrm{R}=$ Jari-jari hidrolik $(\mathrm{m})$

$\mathrm{S}=$ Slope/kemiringan (tidak bersatuan)

$\mathrm{n}=$ Koefisien dasar saluran (tidak bersatuan)

Sesuai dengan Engineering Handbook: Purwanto (2002), penentuan $n$ secara visual dapat dilakukan dengan dua cara pendekatan :

1. Dengan persamaan Cowan, kondisi saluran berdasarkan sifat dan karakter sungai,

2. Sistem tabel, untuk keperluan hasil kasar (perkiraan), penentuan $n$ dapat dilakukan dengan cara membandingkan sifat-sifat dan kondisi saluran yang sudah diketahui nilai $n$-nya.

Kecepatan aliran pada satu penampang saluran tidak sama. Kecepatan aliran ditentukan oleh bentuk aliran, geometri saluran dan faktor-faktor lainnya. Kecepatan aliran sungai diperoleh dari rata-rata kecepatan aliran pada tiap bagian penampang sungai tersebut. Idealnya, kecepatan aliran rata-rata diukur dengan mempergunakan "flow probe" atau "current meter". Alat ini dapat mengetahui kecepatan aliran pada berbagai kedalaman penampang (Rahayu et al, 2009).

Pengukuran debit dilakukan dengan suatu alat pengukur kecepatan aliran yang disebut pengukur arus (current meter). Suatu hubungan tinggi muka air debit, atau kurva debit (rating curve). Kurva debit (rating curve) biasa juga disebut lengkung aliran dibuat memplot debit yang diukur terhadap tinggi muka air pada saat pengukuran (Sangsongko, 1985).

Menurut Rahayu et al (2009), Pengukuran kecepatan aliran dengan metode ini dapat menghasilkan perkiraan kecepatan aliran yang memadai. Prinsip pengukuran metode ini adalah mengukur kecepatan aliran tiap kedalaman pengukuran $(\mathrm{d})$ pada titik interval tertentu dengan current meter atau flow probe. 
Langkah pengukurannya adalah sebagai berikut:

1. Pilih lokasi pengukuran pada bagian sungai yang relatif lurus dan tidak banyak pusaran air. Bila sungai relatif lebar, bawah jembatan adalah tempat pengukuran cukup ideal sebagai lokasi pengukuran

2. Bagilah penampang melintang sungai/saluran menjadi 10-20 bagian yang sama dengan interval tertentu

3. Ukur kecepatan aliran pada kedalaman tertentu sesuai dengan kedalaman sungai pada setiap titik interval yang telah dibuat sebelumnya.

4. Hitung kecepatan aliran rata-ratanya

\section{Sedimen}

Sedimen adalah bahan endapan (butir-butir tanah) baik yang terlarut dalam air maupun yang mengendap yang merupakan hasil keseluruhan erosi pada permukaan tanah, erosi parit, jurang, dan erosi pada tebing-tebing. Sedimen ini diangkut oleh air limpasan permukaan, sebagian diendapkan ditempat-tempat tertentu seperti lekungan tanah, cekungan, atau tempat-tempat yang lebih rendah dan sebagian lainnya masuk kedalam system aliran sungai. Sebagian endapan yang terbawa aliran sungai ini telah diendapkan disungai dan sebagian lainnya terbawa hingga kemuara sungai lalu diendapkan (Mawardi, 2012).

Menurut Hanifah (2014), sedimen dapat berada di berbagai lokasi dalam aliran, tergantung pada keseimbangan antara kecepatan ke alas pada partikel (gaya tarik dan gaya angkat) dan kecepatan pengendapan partikel. Ada 3 (tiga) macam pergerakan angkutan sedimen yaitu:

\section{Bed load Transport}

Partikel kasar yang bergerak disepanjang dasar sungai secara keseluruhan disebut dengan bed load. Adanya bed load ditunjukkan oleh gerakan partikel didasar sungai yang ukurannya besar, gerakan itu dapat bergeser, menggelinding atau meloncat-loncat, akan tetapi tidak pernah lepas dari dasar sungai, pada kondisi ini pengangkutan material terjadi pada aliran yang mempunyai kecepatan aliran yang relative lambat, sehingga material yang terbawa arus sifatnya hanya menggelinding sepanjang saluran.

\section{Wash Load Transport}

Wash load adalah angkutan partikel halus yang dapat berupa lempung (silk) dan debu (dust), yang terbawa oleh aliran sungai. Partikel ini akan terbawa aliran sampai ke laut, atau dapat juga mengendap pada aliran yang tenang atau pada air yang tergenang. Sumber utama dari wash load adalah hasil pelapukan lapisan atas batuan atau tanah didalam daerah aliran sungai. Pada kondisi ini pengangkutan material terjadi pada aliran yang mempunyai kecepatan aliran yang relatif cepat, sehingga material yang terbawa arus membuat loncatan-loncatan akibat dari gaya dorong pada material tersebut.

\section{Suspended Load Transport}

Suspended Load adalah material dasar sungai (bed material) yang melayang di dalam aliran dan terutama terdiri dari butir pasir halus yang mangambang di atas dasar sungai, karena selalu didorong keatas oleh turbulensi aliran. Jika kecepatan aliran semakin cepat, gerakan loncatan material akan semakin sering terjadi sehingga apabila material tersebut tergerus oleh aliran utama atau aliran turbulen ke arah permukaan, maka material tersebut tetap bergerak (malayang) didalam aliran dalam selang waktu tertentu.

Pengertian umum angkutan sedimen adalah sebagai pergerakan butiran-butiran material dasar saluran yang merupakan hasil erosi yang disebabkan oleh gaya dan kecepatan aliran sungai. $\mathrm{Di}$ dalam perhitungan sifat-sifat sedimen yang 
dipakai adalah ukuran, kerapatan atau kepadatan, kecepatan jatuh dan porositas. Laju angkutan sedimen, perubahan morfologi sungai dapat diterankan jika sifat sedimennya diketahui (Wulandari, 1999).

\section{Perhitungan Muatan Layang (Suspended Load)}

Indikator terjadinya sedimentasi dapat dilihat dari besarnya kadar lumpur dalam air yang terangkut oleh aliran air sungai, atau banyaknya endapan sedimen pada badan-badan air dan atau waduk. Makin besar kadar sedimen yang terbawa oleh aliran berarti makin tidak sehat kondisi DAS. Besarnya kadar muatan sedimen dalam aliran air dinyatakan dalam besaran laju sedimentasi (dalam satuan ton atau $\mathrm{m}^{3}$ atau $\mathrm{mm}$ per tahun). Rumus laju sedimentasi harian (Seta,1995):

$$
\text { Qs }=0.0864 \times \text { Cs } \times \text { Q }
$$

Dimana:

Qs = debit sedimen (ton/hari)

$\mathrm{Cs}=$ kadar muatan sedimen $(\mathrm{mg} / \mathrm{l})$

$\mathrm{Q}=$ debit air sungai $\left(\mathrm{m}^{3} / \mathrm{s}\right)$

\section{Pendekatan Lane dan Kalinske}

Lane dan Kalinske,mengasumsikan bahwa muatan melayang dapat dihitung dengan menggunakan rumus (Anas, 2013):

$$
\begin{aligned}
& q_{s w}=q C_{a} P_{L} \exp \left(\frac{15 \omega a}{U_{*} D}\right) \\
& U_{*}=(g D f S)^{1 / 2} \ldots \ldots \ldots \ldots \ldots
\end{aligned}
$$

Dimana:

$$
\begin{aligned}
q_{s w}= & \text { Besar muatan melayang } \\
& \{(\mathrm{kg} / \mathrm{s}) / \mathrm{m}\} \\
q= & \text { Debit aliran per satuan lebar } \\
& \left\{\left(\mathrm{m}^{3} / \mathrm{s}\right) / \mathrm{m}\right\} \\
\omega= & \text { Kecepatan jatuh }(\mathrm{m} / \mathrm{s}) \\
P_{L}= & \text { Koefisien yang bergantung } \\
& \text { pada kecepatan relatif dan } \frac{n}{D f^{1 / 6}} \\
n= & \text { Koefisien manning (tidak } \\
& \text { bersatuan) } \\
a= & \text { Ketebalan muatan dasar }(\mathrm{m}) \\
D f= & \text { Kedalaman aliran }(\mathrm{m}) \\
C_{a}= & \text { Konsentrasi sedimen melayang } \\
& (\text { ppm) } \\
U_{*}= & \text { Kecepatan geser }(\mathrm{m} / \mathrm{s})
\end{aligned}
$$

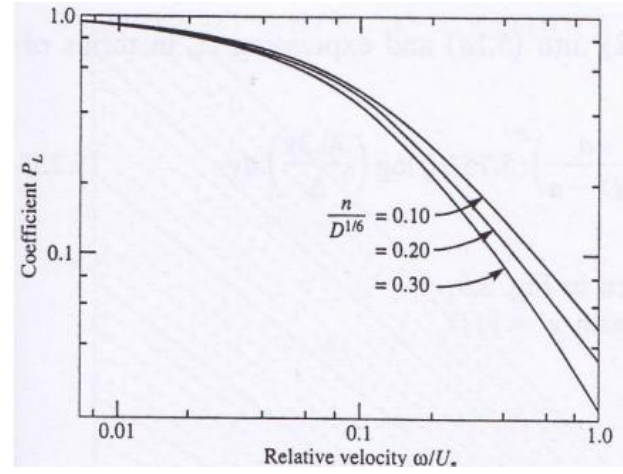

Gambar 1. Hubungan $P_{L}$ dan $\omega / U_{*}$ (Lane dan Kalinske, 1941)

\section{Pendekatan Einsten}

Untuk angkutan sedimen melayang, Einsten mengasumsikan bahwa $\beta=1$ dan $\mathrm{k}=0,4$. Maka kecepatan geser sehubungan dengan kekasaran butir dapat dihitung dengan persamaan (Anas, 2013):

$$
z_{1}=z=\frac{\omega}{0,4 U_{*}^{\prime}}
$$

Dimana :

$$
\omega=\text { kecepatan jatuh partikel }
$$

sedimen berdasarkan $\mathrm{D}_{65}$.

$$
U_{*}^{\prime}=U_{*}=(g R S)^{1 / 2}
$$

Dimana: $\mathrm{m} / \mathrm{s}^{2}$ )

$$
g=\text { percepatan gravitasi }(9,82
$$

$$
\begin{aligned}
& R=\text { Jari-jari hidrolis }(\mathrm{m}) \\
& S=\text { Kemiringan dasar sungai }
\end{aligned}
$$

Persamaan untuk debit sedimen melayang adalah sebagai berikut:

$$
\begin{aligned}
& q_{s w}= \\
& q 11,6 U_{*}^{\prime} C_{a} \alpha\left[\left(2,303 \log \frac{30,2 D f}{\Delta}\right) I_{1}+I_{2}\right]
\end{aligned}
$$

Dimana:

$q_{s w}=$ debit muatan sedimen melayang

(kg/det $/ \mathrm{m})$

$C_{a}=$ konsentrasi sedimen melayang $(\mathrm{g} / \mathrm{l})$

$\alpha=2 \mathrm{xD}_{65}(\mathrm{~m})$

$D f=$ kedalaman aliran $(\mathrm{m})$

$\Delta=\mathrm{D}_{65} / \mathrm{x}$, suatu faktor koreksi yang dapat dilihat pada Gambar 2

$I=$ numerik integritas

Parameter $\mathrm{x}$ : 


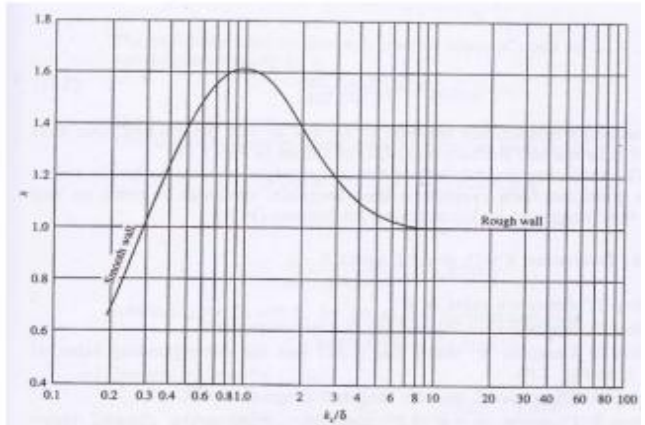

Gambar 2. Faktor koreksi pada distribusi kecepatan logaritmik (Einsten, 1950)

Parameter $I_{1}$ :

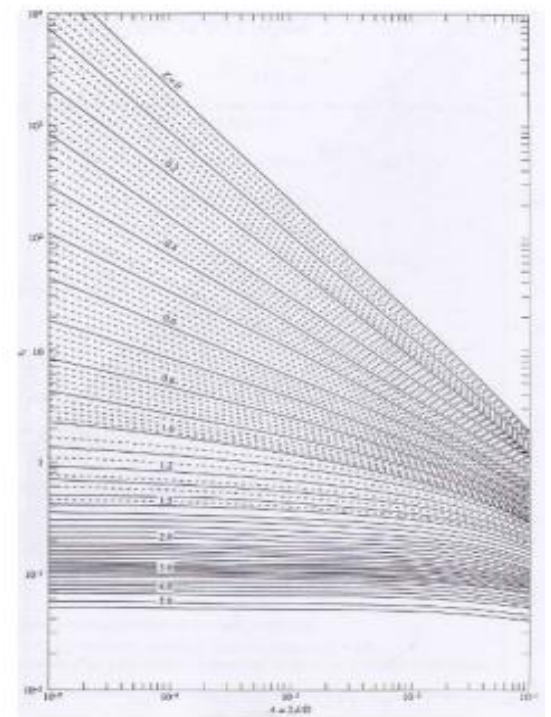

Gambar 3. Fungsi $I_{1}$ pada A untuk harga Z Parameter $I_{2}$ : yang berbeda (Einstein,1950)

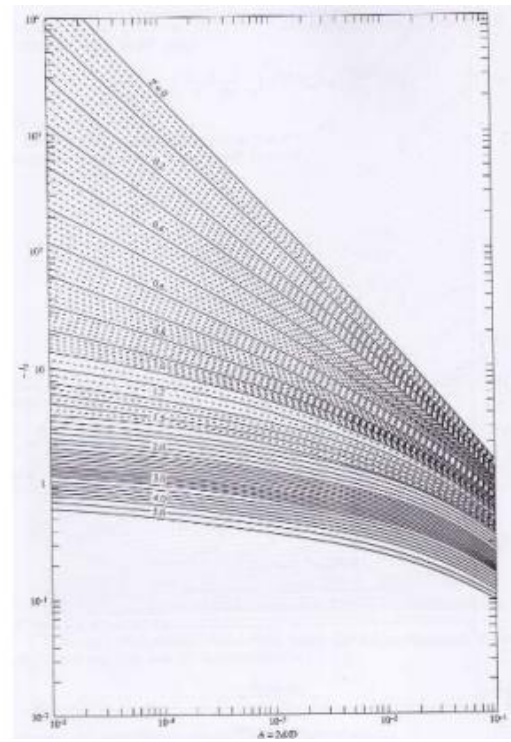

Gambar 4. Fungsi $I_{2}$ pada A untuk harga $Z$ yang berbeda (Einstein,1950)

\section{Regresi}

Regresi dalam statistika adalah salah satu metode untuk menentukan tingkat pengaruh suatu variabel terhadap variabel yang lain (Sunardi, 2009).

Ada beberapa cara untuk menentukan seberapa jauh model matematis regresi sederhana mampu menjabarkan data yang ada. Sesuai atau tidaknya model matematis tersebut dengan data yang digunakan dapat ditunjukkan dengan mengetahui besarnya nilai $r^{2}$ atau juga disebut sebagai koefisien determinasi (Coefficient of determination). Koefisien determinasi dalam statistika dapat diinterpretasikan sebagai proporsi dari variasi yang ada dalam nilai y dan dijelaskan oleh model persamaan regresi. Dengan kata lain, koefisien determinasi menunjukkan seberapa jauh kesalahan dalam memperkirakan besarnya y dapat direduksi dengan menggunakan informasi yang dimiliki variable $\mathrm{x}$. Model persamaan regresi dianggap sempurna apabila nilai $r^{2}=1$. Sebaliknya, apabila variasi yang ada pada nilai y tidak ada yang bisa dijelaskan oleh model persamaan regresi yang diajukan, maka nilai $r^{2}=0$. Dengan demikian, model persamaan regresi dikatakan semakin baik apabila besarnya $r^{2}$ mendekati 1 (Asdak C. 2010).

$$
\begin{aligned}
& r^{2}=\frac{\left[\sum\left(x_{i} y_{i}\right)-\left\{\left(\sum x_{i}\left(\sum y_{i}\right)\right\} / n\right]^{2}\right.}{\left[\sum x_{i}^{2}-\left\{\left(\sum x_{-} i\right)^{2}\right\} / n\right]\left[\left(\sum y_{i}^{2}-\left\{\left(\sum y_{i}\right)^{2}\right\} / n\right]\right.}(9) \\
& \text { Dimana: } \\
& \quad \mathrm{r}^{2}=\text { koefisien determinasi } \\
& \quad \mathrm{n}=\text { jumlah data } \\
& \quad \mathrm{xi}, \mathrm{yi}=\text { data pengamatan lapangan }
\end{aligned}
$$

\section{METODOLOGI PENELITIAN}

\section{Waktu dan Tempat}

Penelitian mengenai "Analisis Perhitungan Debit Muatan Sedimen (Suspended Load) Pada Daerah Irigasi Lekopancing Kabupaten Maros", dilaksanakan pada bulan Oktober hingga November 2016, di daerah Irigasi Lekopancing Kecamatan Tanralili 
Kabupaten Maros Provinsi Sulawesi Selatan.

\section{Alat dan Bahan}

Alat yang digunakan dalam penelitian ini adalah, botol sampel, current meter, oven, timbangan digital, alat uji laboratorium, kalkulator, dan laptop (excel)

Bahan yang digunakan yaitu sampel sedimen, kertas saring, tali rapiah, dan aluminium foil.

\section{Prosedur Kerja}

\section{Penentuan Lokasi}

Lokasi titik pengamatan ditetapkan dengan langkah-langkah sebagai berikut:

1. Meninjau lokasi untuk melihat penampang saluran irigasi Lekopancing.

2. Menentukan titik pengukuran debit dan pengambilan contoh sedimen melayang sebanyak 3 titik pada saluran irigasi dengan jarak 25 meter.

\section{Metode Pengambilan Sampel}

Metode pengambilan sampel yang dilakukan dalam penelitian ini adalah pengambilan sampel secara langsung pada saluran irigasi Lekopancing, yang meliputi:

1. Pengambilan sampel sedimen

Pengambilan sampel sedimen dilakukan dengan menggunakan botol aqua pada titik yang telah ditentukan. Sedimen yang diambil adalah sedimen yang berada dikedalaman $0,5 \mathrm{~h}$.

2. Pengukuran Profil Penampang Saluran

- Lebar dan Kedalaman Penampang Saluran

Prosedur yang dilakukan pada saat pengukuran yaitu:

a. Mengukur dimensi sungai, berupa pengukuran lebar penampang saluran.

b. Memasang tali yang telah dibagi menjadi 5 ruas untuk lebar permukaan air yang telah di tandai dengan jarak masing-masing antar ruas yaitu L/5.

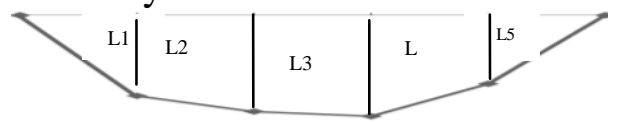

Gambar 5. Metode pembagian patok

c. Membentangkan tali tersebut tegak lurus dengan arah aliran sungai.

d. Mencatat kedalaman pada tiap titik pengukuran.

- Luas Penampang Saluran

Perhitungan luas penampang $\left(\mathrm{m}^{2}\right)$ saluran untuk saluran irigasi dengan menggunakan rumus:

Luas segmen berbentuk trapezium

$$
\begin{aligned}
& \text { Luas }= \\
& \frac{\text { sisikiri }+ \text { sisikanan }}{2} \text { xlebar }
\end{aligned}
$$

- Keliling Basah (P)

Keliling basah $(\mathrm{P})$ adalah panjang garis perpotongan dari permukaan basah saluran dengan bidang penampang melintang yang tegak lurus arah aliran.

- Jari-Jari Hidrolis (R)

Jari-jari hidrolik (R) adalah Rasio luas basah dengan keliling basah dengan menggunakan persamaan:

$$
R=\frac{A}{P} \text {. }
$$

Dimana :

$$
\begin{aligned}
& \mathrm{R}=\text { Jari-jari Hidrolis }(\mathrm{m}) \\
& \mathrm{A}=\operatorname{Luas} \text { Penampang }\left(\mathrm{m}^{2}\right) \\
& \mathrm{P}=\operatorname{Keliling} \text { Basah }(\mathrm{m})
\end{aligned}
$$

3. Pengukuran Kecepatan Aliran

Pada pengukuran kecepatan aliran menggunakan current meter. Pengukuran kecepatan aliran dilakukan untuk mendapatkan kecepatan aliran rata-rata yang akan digunakan untuk menghitung debit sedimen, dengan prosedur berikut:

a. Menetukan saluran ingin diteliti

b. Mengukur kecepatan dengan menggunakan alat current meter 
c. Alat current meter diletakkan dalam aliran air dengan kedalaman 0,6 atau 0,2 dan 0,8 dari kedalam saluran sekunder, didiamkan sejenak hingga nilai yang ditunjukkan pada seven segmen display stabil dan dicatat sebagai besarnya kecepatan aliran

d. Menghitung kecepatan aliran rata-rata dengan menggunakan rumus:

$$
v_{\text {rata }- \text { rata }}=\frac{0,2 v_{p 1}+0,8 v_{p 2}}{\sum \text { titik }} \ldots \ldots .
$$

\section{Dimana :}

$$
\begin{array}{ll}
v_{\text {rata-rata }} & =\text { Kecepatan }(\mathrm{m} / \mathrm{s}) \\
v_{p 1} & =\text { Kecepatan pada titik } \\
& 1(\mathrm{~m} / \mathrm{s}) \\
v_{p 2} & =\text { Kecepatan pada titik } \\
& 2(\mathrm{~m} / \mathrm{s}) \\
\text { titik } & =\text { Banyaknya titik }
\end{array}
$$

\section{Pengujian Sampel Sedimen}

1. Pengujian Diameter Sedimen

Diameter sedimen dapat diketahui dengan menggunakan dua metode yaitu dengan metode analisa saringan dan hidrometer. Untuk pengujian sampel sedimen yang telah kami siapkan adalah pengujian analisa saringan. Adapun langkah-langkah pengujian analisa saringan yaitu:

a. Siapkan sampel kering oven sebanyak \pm 100 gram, yang lolos saringan No. 4.

b. Bersihkan masing-masing saringan \#4, \#10, \#18, \#40, $\# 60$, \#100, \#200, dan pan yang akan digunakan, lalu timbang masing-masing saringan tersebut dan susun sesuai standard yang dipakai.

c. Masukkan sampel kedalam susunan saringan tersebut.

d. Lalu guncangkan saringan selama \pm 15 menit,

e. Setelah dilakukan
pengguncangan, biarkan selama 5 menit untuk memberi kesempatan agar debu-debu mengendap.

f. Timbang berat masing-masing saringan beserta benda uji yang tertahan didalamnya.

2. Pengujian Konsentrasi Sedimen

Konsentrasi sedimen ditentukan dari persentase sedimen dalam sampel sedimen melayang. Adapun cara pengujian sampel sedimen melayang adalah sebagai berikut:

a. Sampel dalam botol dikocok hingga sedimen tercampur merata dengan air

b. Menimbang cawan Petridis, kemudian mengambil sampel air sebanyak $150 \mathrm{~mL}$ yang telah disediakan di dalam gelas ukur dan dituangkan ke Petridis.

c. Memasukkan kedalam oven selama 2 X 24 jam (sampai kering).

d. Menimbang cawan dan air yang sudah di oven tadi. Menghitung nilai sedimen dari selisih berat sebelumnya dengan menggunakan rumus:

$$
C s=\frac{b-a}{\text { Vol.Air }} \text {. }
$$

Dimana :

Cs $=$ konsentrasi sedimen $(\mathrm{g} / \mathrm{l})$

a $=$ berat cawan setelah dioven

(g)

$\mathrm{b} \quad=$ berat cawan sebelum dioven $(\mathrm{g})$

vol.air $=$ Volume air (1)

\section{Perhitungan Debit Muatan Sedimen} Melayang (Suspended load)

1. Lapangan

Perhitungan debit sedimen dengan menggunakan rumus:

$$
Q s=C s x Q_{t o t}
$$

Dimana:

$C s=$ Konsentrasi sedimen $(\mathrm{mg} / \mathrm{l})$ 


$$
\begin{aligned}
Q_{\text {tot }}= & \text { debit total sungai melalui } \\
& \text { metode langsung dan } \\
& \text { manning }\left(\mathrm{m}^{3} / \mathrm{s}\right) \\
Q s= & \text { Debit sedimen }(\mathrm{kg} / \mathrm{s})
\end{aligned}
$$

2. Pendekatan Lane dan Kalinske

Perhitungan sedimen dengan pendekatan Lane dan Kalinske menggunakan persamaan (4) kemudian untuk mendapatkan debit muatan sedimen yaitu dengan menggunakan rumus:

$$
Q s=W x q_{s w}
$$

Dimana:

$$
\begin{aligned}
q_{s w} & =\text { debit muatan sedimen } \\
& \text { melayang }(\mathrm{kg} / \mathrm{s} / \mathrm{m}) \\
W & =\text { lebar dasar }(\mathrm{m}) \\
Q s & =\text { Debit sedimen }(\mathrm{kg} / \mathrm{s})
\end{aligned}
$$

3. Pendekatan Einsten

Perhitungan sedimen dengan pendekatan

Einsten

menggunakan persamaan (8)

kemudian untuk mendapatkan debit muatan sedimen yaitu dengan menggunakan (15).

\section{Analisis Debit Sedimen}

Analisis debit sedimen digunakan dengan menggunakan metode statistik regresi dengan membandingkan debit sedimen lapangan dengan debit sedimen yang didapatkan dari pendekatan Lane dan Kalinske serta pendekatan Einsten dengan menggunakan rumus (9).

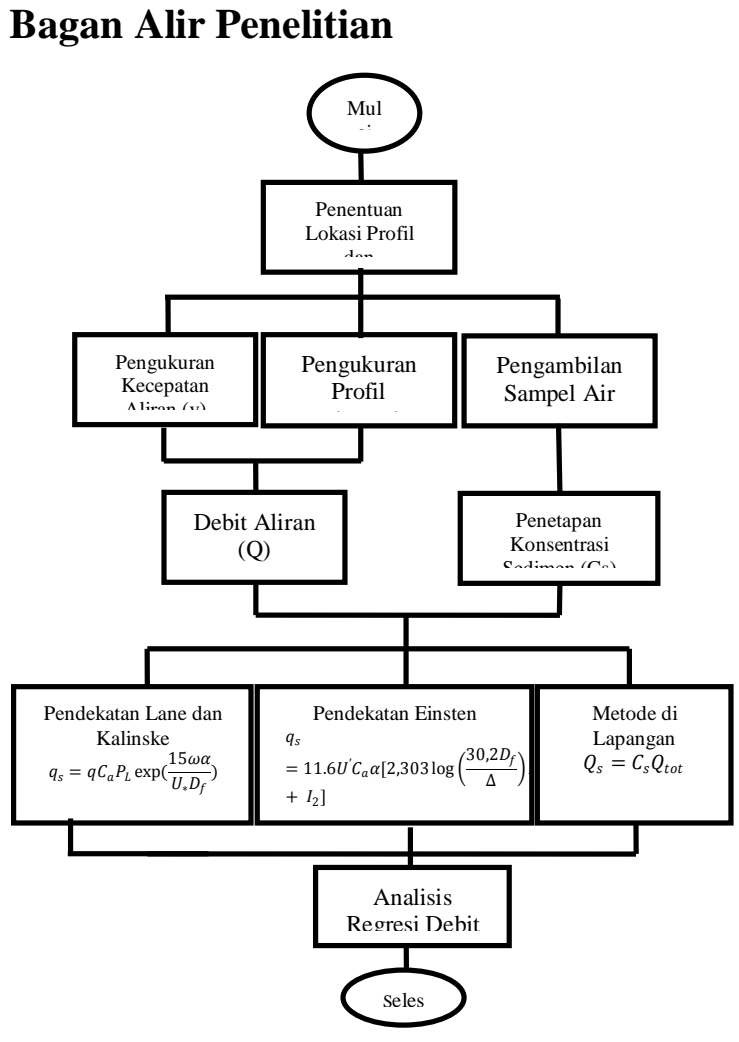

HASIL DAN PEMBAHASAN

Keadaan Umum Lokasi

Daerah Irigasi Lekopancing terletak di Kecamatan Tanralili, Kabupaten Maros, Provinsi Sulawesi-Selatan. Secara geografis daerah irigasi Lekopancing terletak di 5'7'41.37’ LS dan $119^{\circ} 38^{\prime} 19.20^{\prime \prime}$ BT. Batas-batas wilayah penelitian yaitu, sebelah utara berbatasan dengan desa Kurusumange, sebelah selatan berbatasan dengan desa Purna Karya, sebelah barat berbatasan dengan Kecamatan Mandai, dan sebelah timur berbatasan dengan Kecamatan Tompobulu.

Daerah Irigasi Lekopancing memiliki luas 3.626 ha, dengan panjang saluran induk $5.765 \mathrm{~m}$, dan panjang saluran sekunder $28.395 \mathrm{~m}$, dengan lebar rata-rata saluran irigasi $6 \mathrm{~m}-10 \mathrm{~m}$ (psdasulsel, 2017).

Iklim di Kecamatan Tanralili yaitu tipe B menurut Schmidth Ferguson dengan kriteria sebagai daerah basah dengan vegetasi hutan hujan tropika. Dimana 
musim hujan terjadi periode bulan Oktober sampai Maret dan musim kemarau dalam bulan April sampai September (Badan Metereologi Klimatologi dan Geofisika, Stasiun Klimatologi Kelas I Maros, 2013).

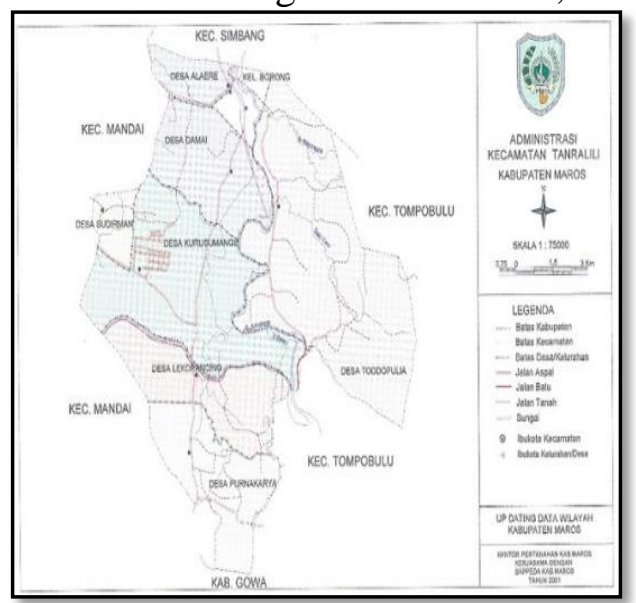

Gambar 6. Peta Lokasi Penelitian

\section{Debit Sedimen Melayang Pada Tiap Penampang}

Hasil debit sedimen melayang pada saluran irigasi Lekopancing di setiap penampang saluran yaitu:

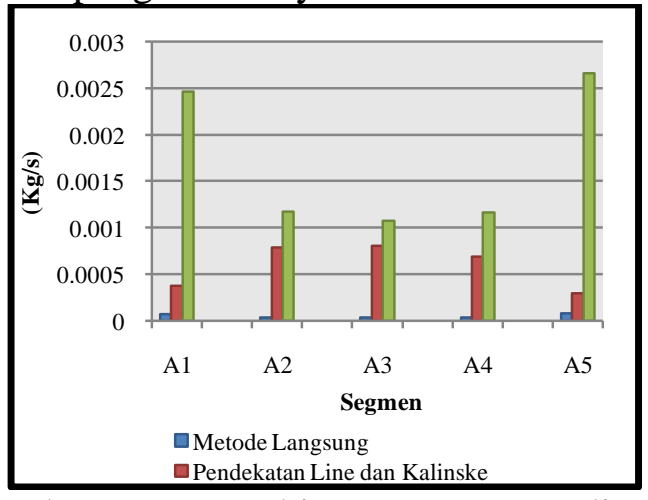

Gambar 7. Debit muatan sedimen melayang (suspended load) pada irigasi Lekopancing penampang A

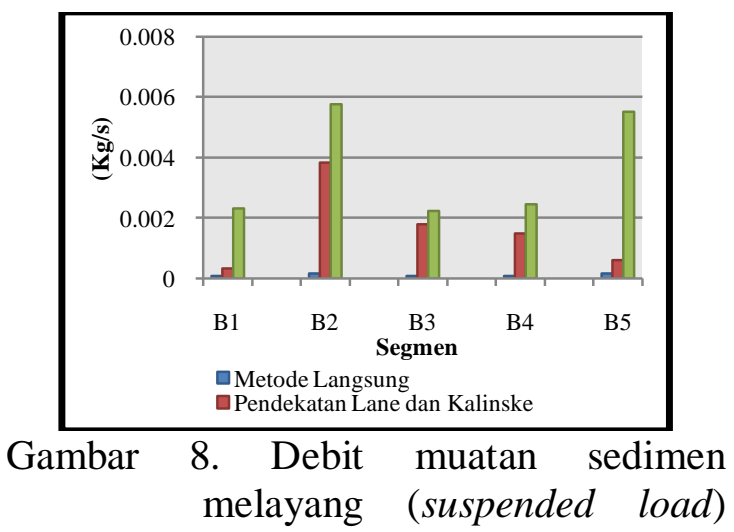

pada irigasi Lekopancing penampang $\mathrm{B}$

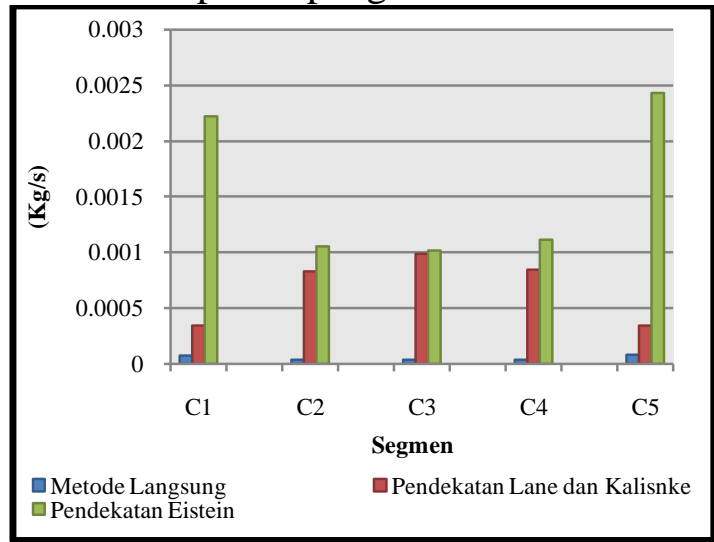

Gambar 9. Debit muatan sedimen melayang (suspended load) pada irigasi Lekopancing penampang $\mathrm{C}$

Jumlah debit muatan sedimen melayang di segmen $A_{1}$ dan $A_{5}$ (Gambar 7) serta $C_{1}$ dan $C_{5}$ (Gambar 9) lebih tinggi dibanding dengan jumlah debit muatan sedimen melayang yang berada di tengah saluran. Hal ini disebabkan adanya aktivitas penduduk di sekitar daerah irigasi yang menyebabkan tingginya aktivitas laju erosi. Hal ini sesuai dengan pendapat Komaruddin (2008), yang menyatakan bahwa aktivitas manusia dalam pengelolahan lahan merupakan faktor terbesar terhadap erosi di suatu DAS. Selain itu, faktor kemiringan saluran serta vegetasi yang tumbuh di sekitar daerah irigasi juga mempengaruhi tingginya debit muatan sedimen yang berada di pinggir saluran.

Berbeda dengan debit muatan sedimen yang ditunjukkan oleh Gambar 8 . dimana jumlah debit muatan sedimen melayang yang berada di segmen $\mathrm{B}_{2}$ dan $\mathrm{B}_{5}$ lebih tinggi dibanding dengan jumlah debit muatan sedimen yang berada di segmen $B_{1}, B_{3}$, dan $B_{4}$. Tingginya debit muatan sedimen melayang yang berada di segmen $\mathrm{B}_{2}$ diakibatkan oleh tingginya kecepatan aliran (v) air. Hal ini dikarenakan kerusakan dinding irigasi penampang B dan adanya tanaman (lumut) di dinding irigasi.

Pengukuran debit muatan sedimen metode langsung mempunyai hasil yang 
lebih rendah dibandingkan dengan dua metode perhitungan yang digunakan yaitu metode perhitungan pendekatan Lane dan Kalinske dan pendekatan Einstein. Hal ini disebabkan pada pengukuran debit muatan sedimen (langsung) hanya menggunakan beberapa parameter seperti profil ukuran saluran, kecepatan aliran, dan besarnya sedimen melayang yang didapatkan di saluran irigasi. Sedangkan, debit muatan sedimen melayang yang dihasilkan dari kedua metode pendekatan memperhitungkan viskositas kinematik $(v)$, kecepatan jatuh $(\omega)$ partikel sedimen.

Perbedaan debit muatan sedimen melayang pada pengukuran langsung dengan perhitungan pendekatan Lane dan Kalinske berbanding terbalik. Dan metode perhitungan pendekatan Einstein berbanding lurus dengan pengukuran langsung. Hal ini disebabkan karena pada metode perhitungan pendekatan Lane dan Kalinske menggunakan beberapa parameter yaitu nilai $\mathrm{P}_{\mathrm{L}}$ yang tergantung dari koefisien manning (n) saluran irigasi dan berbanding terbalik dengan nilai kecepatan geser (U*) sedimen yang dihasilkan.

\section{Debit Muatan Sedimen Melayang (Suspended Load) di Saluran Irigasi Lekopancing}

Hasil debit sedimen melayang pada saluran irigasi Lekopancing saluran irigasi Lekopancing yaitu:

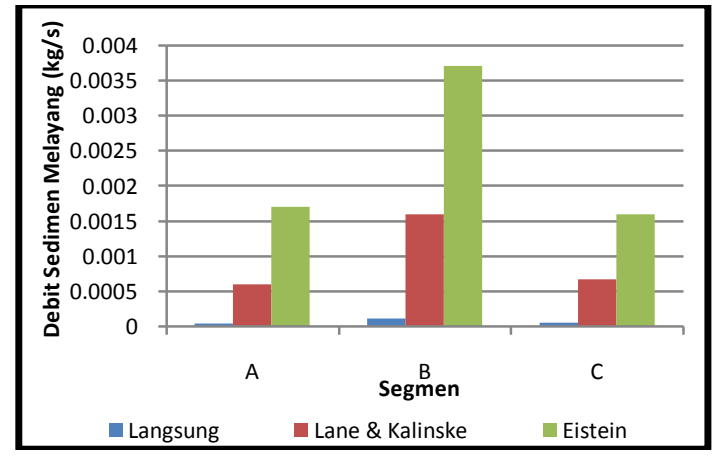

Gambar 10. Debit Muatan Sedimen Melayang Penampang Melintang

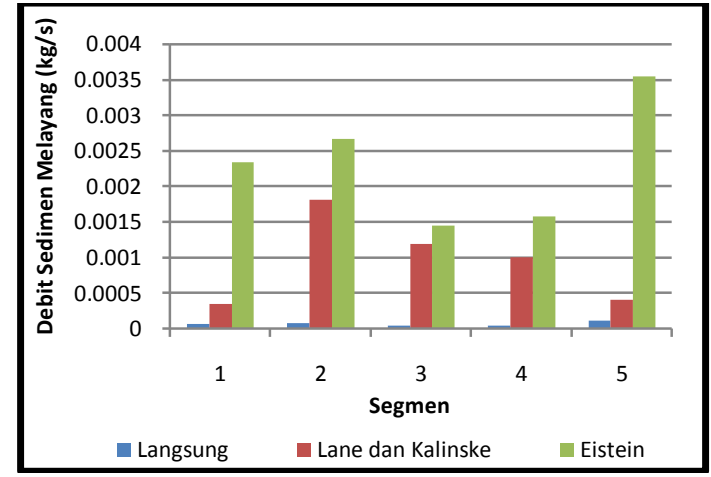

Gambar 11. Debit Muatan Sedimen Melayang Penampang Memanjang

Pada perhitungan muatan sedimen melayang (susupended load) di saluran irigasi Lekopancing-Maros, debit muatan sedimen terbesar berdasarkan penampang melintang saluran (Gambar 10) berada pada segmen B disetiap pengukuran langsung, pendekatan Lane dan Kalinske, dan pendekatan Einstein. Hal ini dikarenakan adanya kerusakan pada dinding saluran irigasi di sekitar segmen B yang mengakibatkan tingginya debit muatan sedimen di daerah tersebut.

Berbeda dengan debit muatan sedimen melayang penampang memanjang (Gambar 11), debit sedimen terbesar berada di segmen 5 untuk pengukuran langsung dan pendekatan Einstein. Hal ini dikarenakan segmen ini merupakan pinggir saluran irigasi yang biasanya dipengaruhi oleh faktor terjadinya erosi yaitu manusia dan vegetasi di sekitar saluran. Sedangkan tingginya debit muatan sedimen yang berada di segmen 2 pada pendekatan Lane dan Kalinske diakibatkan karena tingginya kecepatan aliran di segmen tersebut. Hal ini didukung oleh Chow (2009), yang menyatakan bahwa kecepatan aliran maksimum sering ditemukan pada permukaan bebas dari kekasaran saluran.

Hubungan Pengukuran $r$ Langsung
Debit Muatan Sedimen Melayang
(Suspended Load) dengan Pendekatan
Lane dan Kalinske dan Pendekatan
Einstein Pada Irigasi Lekopancing

Hubungan Pengukuran Langsung Debit Muatan Sedimen Melayang (Suspended Load) dengan Pendekatan Lane dan Kalinske dan Pendekatan Einstein Pada Irigasi Lekopancing 
Hubungan pengukuran langsung debit muatan sedimen melayang dengan pendekatan Lane dan Kalinske dan pendekatan Einstein pada saluran irigasi Lekopancing di penampang melintang dan memanjang saluran irigasi Lekopancing yaitu:

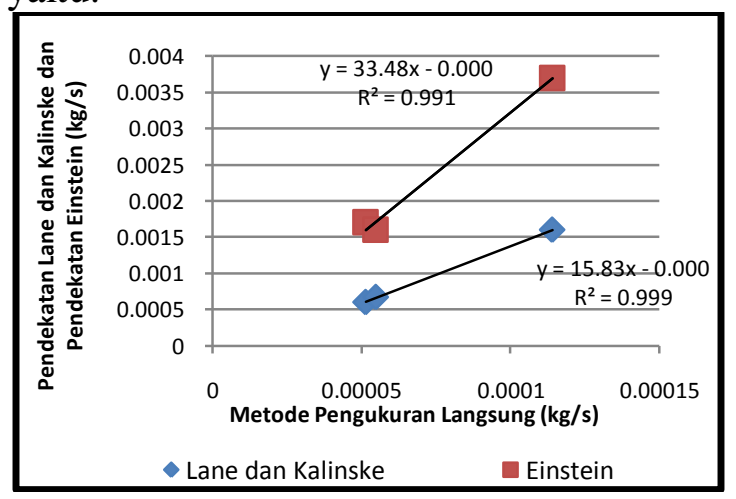

Gambar 12. Hubungan debit muatan sedimen melayang langsung dan pendekatan Lane dan Kalinske dan pendekatan Einstein Pada Penampang Melintang

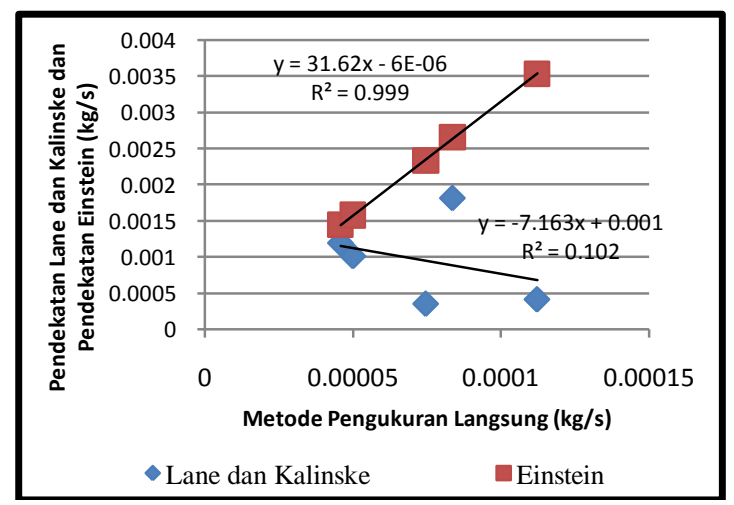

Gambar 13. Hubungan debit muatan sedimen melayang langsung dan pendekatan Lane dan Kalinske dan pendekatan Einstein Pada Penampang Memanjang

Grafik yang ditunjukkan oleh Gambar 12. pada pengukuran debit muatan sedimen di daerah irigasi Lekopacing secara melintang menunjukkan bahwa kedua pendekatan Lane dan Kalinske dan pendekatan Einstein menunjukkan nilai $\mathrm{R}^{2}$ yaitu 0.991 dan 0.999. Hal ini menandakan kedua pendekatan ini menunjukkan nilai hubungan yang baik. Begitupun dengan nilai $\mathrm{R}^{2}$ yang dihasilkan pada pendekatan
Einstein di penampang memanjang (Gambar 13) saluran irigasi Lekopancing yaitu 0.999, hal ini didukung oleh pendapat Asdak (2010), yang menyatakan bahwa model persamaan $\mathrm{R}^{2}$ dikatakan baik apabila besarnya mendekati 1 . Sedangkan pada pendekatan Lane dan Kalinske pada penampang memanjang (Gambar 13) memiliki nilai $\mathrm{R}^{2}$ yaitu 0.102 yang berarti memiliki nilai korelasi yang kurang baik.

\section{KESIMPULAN}

\section{Kesimpulan}

Kesimpulan dari penelitian dapat disimpulkan sebagai berikut:

1. Debit muatan sedimen melayang tertinggi berada di segmen B yaitu $1,14 \times 10^{-4} \mathrm{~kg} / \mathrm{s}$ (metode langsung), $1,6 \times 10^{-3} \mathrm{~kg} / \mathrm{s}$ (Pendekatan Lane dan Kalinske), dan $3,7 \times 10^{-3} \mathrm{~kg} / \mathrm{s}$ (Pendekatan Einstein).

2. Perhitungan debit pada penampang melintang saluran irigasi Lekopancing pada pendekatan Lane dan Kalinske serta pendekatan Einstein memiliki hubungan korelasi yang baik dengan metode pengukuran langsung. Sedangkan, pada penampang memanjang saluran irigasi, pendekatan Einstein memiliki korelasi yang baik dengan pengukuran langsung dan pendekatan Lane dan Kalinske memiliki korelasi yang kurang baik.

3. Debit muatan sedimen tertinggi berada dipinggir saluran irigasi Lekopancing karena dipengaruhi oleh faktor vegetasi, kemiringan saluran, dan manusia.

\section{DAFTAR PUSTAKA}

Anas, H. 2013. Studi Experimen Hubungan Besarnya Aliran Air dengan Total Angkutan Sedimen Pada Saluran Terbuka. Universitas Hasanuddin: Makassar.

Asdak, C. 2010. Hidrologi dan Pengelolaan Daerah Sungai. Gadjah Mada University Press: Yogyakarta. 
Badan Metereologi Klimatologi dan Geofisika, Stasiun Klimatologi Kelas I Maros. 2013. BMKG: Maros.

Badan Sumber Daya Alam Sulawesi Selatan. $2017 . \quad$ Database Irigasi.http://mamminasata.psdasuls el.org/index.php/database/irigasi/2 diakses pada tanggal 2 April 2017.

Chow, V. T. 2009. Open-Channel Hydraulics. The Blackburn Press.

Komaruddin, N. 2008. Penilaian Tingkat Bahaya Erosi di Sub Daerah Aliran Sungai Cileungsi, Bogor. Fakultas Pertanian Universitas Padjajaran: Bandung.

Mawardi, M. 2012. Rekayasa Konservasi Tanah dan Air. Yogyakarta: Bursa Ilmu.

Peraturan Pemerintah No. 252001. Tentang Sumber Daya Air. Jakarta.

Radjualini. 2008. Perencanaan Sistem Irigasi. Pendidikan Teknik Sipil Universitas Pendidikan Indonesia: Bandung.

Rahayu, S. dkk. 2009. Monitoring Air di Daerah Aliran Sungai. World Agroforestry Center ICRAF Asia Tenggara: Bogor.

Rangga, M. A. P. 2012. Studi Efisiensi Pemberian Air Irigasi Desa Kutoharjo, Kecamatan Pati, Kabupaten Pati, Jawa Tengah. Universitas Negeri Semarang: Semarang.

Sangsongko, D. 1985. Teknik Sumber Daya Air. Erlangga: Jakarta.

Seta, A.K. 1995. Konservasi Sumber Daya Tanah dan Air Cetakan Kedua. Penerbit Kalam Mulia: Jakarta.

Sunardi, N. 2009. Pengantar Statistika. Bumi Aksara: Jakarta.

Triatmodjo, B. 2010. Hidrologi Terapan. Beta Offset: Yogyakarta.
Wulandari, E. 1999. Pengaruh Perubahan Penggunaan Lahan terhadap Laju Sedimentasi Waduk Wonorejo. Universitas Brawijaya: Malang. 